\title{
The Struggle with Anxiety and Depression among the Elderly: Predicting Elderly Behavior in Crisis and Conflict Situations-The Case of Operation Protective Edge
}

\author{
Avi Bitzur ${ }^{1,2}$ \\ ${ }^{1}$ The Head of National Security and Homefront Defense Studies at Beit Berl Academic College, Israel \\ ${ }^{2}$ The Head of Applied Gerontology Studies at the Academic Center of or Yehuda, Israel \\ Correspondence: Avi Bitzur, the Head of National Security and Homefront Defense Studies at Beit Berl Academic \\ College, Israel.
}

Received: November 28

doi:10.11114/ijsss.v5i2.2013

\author{
Accepted: December 19, $2016 \quad$ Available online: December 26, 2016 \\ URL: http://dx.doi.org/10.11114/ijsss.v5i2.2013
}

\begin{abstract}
Existing theories cast the elderly as individuals likely to crumble under pressure, suggesting that crisis situations may exacerbate underlying conditions, such as depression.

The conflict between Israel and the Palestinians breeds numerous stress situations, which are bound to affect the lives of the elderly population on both sides. This inspired the author to examine whether the elderly population in Israel does, in fact, behave according to existing theories.

A prominent example of a crisis situation was the 2014 conflict, which triggered a crisis in Israeli communities that found themselves under the threat of direct rocket fire. The situation lent itself to the assumption that there would be a spike in depression and anxiety among the area's residents, especially the elderly, which would translate into "mass migration" to safer areas.

This study sought to substantiate or refute the "helplessness" of elderly people in crisis situations. It was based on a qualitative analysis of questionnaires answered by Holocaust survivors, former Soviet Union immigrants, and long-time residents of the Gaza vicinity communities, shortly after the conflict.

The study found little to no evidence of depression or anxiety among elderly Israelis, proving their resilience in the reviewed crisis.

While the rationale varied among participants, a clear sentiment came through, spelling devotion among the border communities' residents, defiance among immigrants from the former USSR, and a combination of both among Holocaust survivors.

The study indicated the elderly tend to be mentally tougher than younger generations, proving their resilience by weathering multiple threats. To conclude: Senior citizens can be used to bolster the home front's resilience; depression and anxiety experienced by the elderly in crisis situations can be alleviated by providing them with information about the nature of the threat; and it is best to form permanent resilience centers in threatened areas.
\end{abstract}

Keywords: anxiety, depression, elderly, stress situation, civilian, home front defense, resilience, conflict

\section{Introduction}

In August 2007, a new government ministry (Note 1) was formed in Israel, the Pensioners Affairs Ministry (Note 2). The office, formed by Minister Rafael Eitan and the author of this paper, was established with the purpose of dealing with issues pertaining to Israel's elderly population.

Early on, the minister and I debated what name - "senior citizens," "elderly affairs," or "pensioners' affairs" - would best serve the ministry's purpose. Almost immediately it became clear that the word "elderly" evoked strong and unequivocally negative reactions, mostly over the fact that its Hebrew equivalent - "kashish" - brings to mind a frail and helpless image; one of something as brittle as straw. Those opposing the idea insisted elderly Israelis do not perceive themselves as weak or helpless, but rather as unbreakable. But are they? 
Old age has been the subject of numerous studies, but this paper seeks to focus on one repetitive aspect, which presents the elderly as fragile individuals who may buckle under the pressure of certain circumstances, especially crisis situations (Ruth \& Coleman, 1996). This position is consistent and assumes that conditions such as anxiety, fear of death (Feifel, 1977, Branscomb, 1973), clinical depression (Riegel, 1976), change in social status (Ibid) etc. will be exacerbated by extreme stress situations, such as war or terrorist attacks.

Academic research often classifies stress situations as "negative life events" and focuses on their implications on the welfare of the elderly (Denise \& Wise, 1991). This sphere of events includes retirement, widowhood, health issues, or the so-called "Empty Nest Syndrome" (Nowolin \& Siegler, 1993).These events are seen as catalysts that may increase the elderly's likelihood to collapse under the weight of their own objective reality.

But is this axiom true? Are the elderly so vulnerable to "negative life events" that they experience mental breakdowns more often than younger populations?

This paper will examine the effects of a specific "negative life event," namely 2014's Operation Protective Edge in the Gaza Strip, in an attempt to undermine the validity of this axiom, and offer a fresh perspective on how elderly Israelis deal with crisis situations.

The arguments will be based on data derived from a study that examined social, economic, political, psychological, and organizational resilience in Israeli society during the military operation waged over the summer of 2014 (Note 3). This military campaign constituted a "conflict situation" that naturally represented an extreme stress scenario, during which the civilian home front, on both sides, came under attack. The research sample included individuals aged 65 and over (Note 4), and their answers illustrated elderly Israelis' resilience in different categories.

This paper will begin with an abstract of Operation Protective Edge; continue with a short review of the study on which the author has based his principal findings; and continue to discuss the conclusions and recommendations on utilizing the abilities demonstrated by the elderly to bolster society's stability and resilience vis-à-vis any threats it may face, both foreign and domestic.

\section{Operation Protective Edge as an Example of an Extreme Stress Situation for the Home Front}

Operation Protective Edge (Note 5) was a military campaign waged in the summer of 2014, which saw the Israel Defense Forces clash with Hamas and the Palestinian population in the Gaza Strip. Naturally, multiple military targets were struck, but this paper will focus on the fact that multiple civilian locations, on both sides, were attacked as part of the fighting, during which Hamas:

- Targeted Israeli communities located 40 kilometres (25 miles) and farther from the Gaza Strip with missile fire.

- Targeted Israeli communities located as far as 10 kilometres (6 miles) from Gaza with rocket fire.

- Targeted Israeli communities located 5 kilometres (3 miles) or closer to Gaza with mortar fire.

- Launched naval raids and used terror tunnels to infiltrate border-adjacent Israeli communities and stage terrorist attacks.

The operation was "a difficult time for the residents of the Western Negev" (Note 6). Many of them experienced distress due to the sense of danger and the threat of terror, which became part of the daily routine in a geographical area stretching from the southern cities of Ashdod and Ashkelon, to Beersheba, Ofakim, Rahat and Arad, and the southern border-adjacent communities (Note 7).

This was a classic example of a prominent crisis situation that had significant ramifications on the public's daily routine, especially for those living within 25 miles from the Gaza Strip, i.e. within Hamas rocket range.

Logic would have you believe that some of the following potential ramifications would cause the population anxiety:

- Multiple casualties and fatalities as a result of rocket fire.

- An acute sense of uncertainty and stress among the area's residents over the inability to predict where rockets would strike.

- Sustaining multiple missile and mortar attacks - projectiles that are particularly destructive.

- Fear of an invasion by hostile elements via underground terror tunnels - sudden attacks with no warning signs.

To say that Operation Protective Edge presented a coping challenge for Israeli society, and especially for the communities within 25 miles of the Gaza Strip, would be an understatement. This conflict can be considered a "war" in every respect, and it therefore meets the classic definition of a crisis situation that tests the population's mental 
resilience, including that of the elderly.

Current studies and our own stigmatic expectations as to the elderly's potential reaction to extreme stress situations of this nature would have us believe that they will demonstrate low resilience levels, especially given the threats presented during Operation Protective Edge.

Many residents of the Gaza-vicinity communities left the area during the fighting, and one would think the elderly would have led this trend. We would also expect phenomena such as insomnia, psychosomatic episodes, and seclusion tendencies (Note 8) to characterize mostly the elderly population living in the areas most affected by the fighting.

\section{The Elderly Approach to Dealing with Extreme Stress Situations}

Dealing with these phenomena in order to delay, resolve or alleviate extreme stress situations among the elderly should incorporate multiple resources, both external and internal. External resources should include a belief system, education, cultural exposure and information, which must correspond with individual internal resources, such as ethnicity and faith, cultural background, socioeconomic situation, ideology, and prior experience with crisis situations.

This combination can be used to foster resilience, which would allow the elderly to function on personal, technical, cultural, economic, and environmental levels (Lazarus, 2000).

The aforementioned should afford the elderly the ability to withstand crisis situations, providing all the components described are working harmoniously, especially given the fact that research literature argues the opposite, saying the elderly and their environment do not combine said resources to bolster themselves opposite extreme situations.

The threat posed by a military conflict, as manifested during Operation Protective Edge, is an opportunity to review a number of key issues that are the basis for examining the elderly's resilience and their contribution to the community:

- Did the elderly living within immediate rocket range lack the ability to withstand the threat?

- Was there an increase in anxiety and depression following the crisis elements that manifested during the military campaign?

- What increased resilience among the elderly, if at all?

- What are the conclusions and the immediate significant recommendations derived from the behavioral analysis of elderly Israelis during the operation?

An examination of the data, against the backdrop of the operation, is crucial to understand the elderly's psyche, vulnerability, vitality and their contribution to their communities.

The common perception that sees the elderly as threatened, anxious, depressed, and fragile individuals must be reviewed: Today's geophysical and geopolitical situation, the need to foster resilience on individual, familial, communal and social levels, and the overall need to strengthen these factors' objective stability and resilience, require multiple financial, political, military, technological, and - above all - priceless human resources, one of which is our elderly. They have a wealth of experience, ability, knowledge, and time that could be used to realize the aforementioned objectives.

This understanding needs to be reinforced, but only after being put to the test. Operation Protective Edge presents an opportunity to examine the so-called "elderly" resource in real time, when these individuals were under tangible threat, as a personal sense of safety is the most basic of needs if one is to achieve the calm needed to face extreme stress situations (Hobfoll, 1988). Have elderly Israelis been able to achieve this goal? And if so, how will it benefit us, as a society?

The results of the military campaign and its implications on the resilience demonstrated by the residents of the western Negev were the basis for a study conducted by the Sapir Academic College on civilian resilience in the area (Rosset, Tzur \& Bibi, 2015).

The study reviewed the resilience of Israeli civilians under attack. Researchers formulated an index, the "Sapir Barometer," which was based on resilience factors' analysis, surveys, and integrative data analysis across five parameters also relevant to the elderly - those allegedly prone to buckling under pressure - including, personal resilience, community cohesion, confidence, financial situation, and faith in the local or national leadership.

The study found a clear increase in the number of civilians who sought psychological support, but only a fraction of them were elderly. Moreover, researchers found that the elderly population demonstrated significantly higher resilience compared to other sample groups.

These findings illustrate counterintuitive reality that undermines the common perception of the elderly as feeble, depressed, anxious and the most likely to crumble under pressure: 
"The resilience index of the Israeli population under attack during Operation Protective Edge is 59.4 out of 100. Respectively, elderly resilience among the same population is 60.6 for those ages 56-65; 62.7 for those ages 66-75; and 67.6 for those ages 76+" (Sapir Barometer, p.4).

Defining and understanding the concept of resilience refers to one's ability to cope with difficulties and crises without experiencing cognitive, emotional, financial, and psychological breakdowns. This kind of crisis management accounts for environmental factors, as well as personal, cultural, social, and economic ones. This is my chosen viewpoint when addressing the issue of how our elderly cope with such situations, as well as with symptoms of depression and anxiety. The study's valid findings indicate they deal with these situations successfully, demonstrating their resilience.

This analysis of the findings will incorporate the abundance of theoretical material available on depression, anxiety, and mental resilience among the elderly. While the recommendations put forth focus on Israeli society, they could be used by any human society seeking to steady itself vis-à-vis the threats it faces.

\section{Elderly Resilience - Findings and Conclusions}

Resources and resilience are the two most prominent elements when dealing with extreme crisis situations, such as war (Sapir Barometer, p.6). The elderly individual's internal resources, such as personal traits, faith, cognitive style (Note 9), life experience, and experience with previous crisis situations, combined with external resources, such as social support (Hobfoll, 1988), the use of psychological resilience centers (Note 10), relevant information provided ahead of time, and the availability of material and financial resources, will all produce a stronger and more resilient elderly individual, who is able to deal with crisis situations, such as war, with relative ease.

Early on, the study found that the elderly population in the area surveyed did not experience unusual anxiety or depression, thus proving their resilience. The elderly population was found to be surprisingly immune - in substantially higher percentages than other sample groups - and was found to have demonstrated impressive strength. A prominent example of this spirit was the utter refusal of the residents of a nursing home in Kibbutz Yad Mordechai, about 7 kilometres (4 miles) from the Israel-Gaza Strip border, to evacuate the area - contrary to the Welfare Ministry's orders.

Explaining the elderly's resilience and their ability to avoid increased anxiety and depression in this context corresponds with their placement within specific groups, illustrating the social stereotypes in the area's communities.

Expressions of elderly resilience were found to correspond with the residential areas affected by the conflict, as demonstrated by the participants' statements (according to the various groups' typical archetype):

- The founders' generation in the border-adjacent communities expressed devotion: "This is a war for our home, and I won't abandon my home."

- Former USSR immigrants living in Ashdod and Ashkelon expressed defiance: "They [the enemy] will learn aggression will be met with aggression. We're not going anywhere."

- Holocaust survivors (Note 11) residing in the area expressed a combination of both: "There's nothing they can do to us that hasn't already been done."

The study indicated the elderly tend to be more psychologically resilient than the younger generations, and it is therefore important for society to use it to learn how to treat its elderly population. Moreover, it would be best to use the resilience found among the elderly to inspire and bolster similar foundations among other age groups.

The findings and conclusions contradict common theoretical concepts and position the elderly in places society should address, especially in these troubled times, when almost every nation worldwide is facing both internal and external threats.

The findings and conclusions focus on four major issues:

- The elderly fearlessly confronted the threat, proving immunity and resilience (70\% according to the Sapir Barometer, compared to $60 \%$ among the younger and middle generations).

- Elderly resilience is the product of internal and external resources, later bolstered by psychological resilience centers. This combination prevented extreme stress situations and, in turn, prevented the development of anxiety and depression.

- The absence of information was found to be crucial to the elderly's frame of mind: Their resilience was unaffected by rocket fire, but was rattled by the unfamiliar concept of terror tunnels. This was a major cause for concern for the general public, but especially for the elderly, who simply did not know what to expect from the tunnel threat. It seems an unfamiliar issue was a cause for anxiety and concern among the elderly. 
- $\quad$ Elderly Israelis are a vital yet untapped resource in home front defense (Harkabi, 1990). Separating civilian defense into the two familiar categories of passive and active defense, the elderly are a resource that could be used to bolster social resilience as part of passive civilian defense, via lectures, conversations, and personal example set by the elderly to other age groups, in order to inspire mental, cognitive, and physical resilience.

\section{Conclusions and Recommendations}

The reality we face today is one of a world threatened by terrorism as well as natural disasters, such as tsunamis and earthquakes. The free world's struggle against those who threaten its integrity, stability, and resilience, requires any and all available resources to bolster and stabilize the principles of liberty, democracy, and equality against those who would see them destroyed.

We have become accustomed to ignoring the priceless resource that is our elderly, who possess incomparable experience, knowledge and wisdom. We would be wise to implement the following recommendations when reviewing the struggle against anxiety and depression among the elderly, and the ways in which this sector may be incorporated in the struggle to counter the threats the home front faces:

- The elderly can become an important part if the elements comprising the home front's immunity and resilience vis-à-vis various threats.

- $\quad$ Stress situations among the elderly must be addressed without delay, among other things by providing them with comprehensive, real-time information about projected threats.

- It is advised to form permanent psychological resilience centers in threatened areas, where some services would cater to the elderly.

- An emphasis must be placed on bridging intergenerational gaps between the old and the young. Younger generations will benefit from such interaction and aspire to imitate their elders, who have - and are standing steadfast in the face of adversity.

The issue of anxiety and depression is a serious one, and it must be dealt with constantly and tirelessly, but it also requires the understanding that in some cases, our elderly are able, capable, worthy and in fact are doing much more than what is allegedly expected of them. "Do not cast me away when I am old" (Psalms 71:9) is not simply a principle to live by, but rather an ideal that masks a world of strength, stability, and resilience worthy of imitation.

\section{Notes}

1. The Israeli Senior Citizens Ministry is one of only a handful of similar ministries worldwide, such as, for example, in Australia

2. The ministry was renamed twice: in 2013, under the late Minister Uri Orbach, it was renamed "Senior Citizens Ministry," and in 2015, under Minister Gila Gamliel it was renamed the "Social Equality Ministry."

3. The study on the social resilience of southern communities during Operation Protective Edge was conducted by the Sapir Academic College in Sderot, and included the researchers and their assistants, who came together to present southern residents' resilience while under threat.

4. The ages referred to in this study are the chronological ages as defined in Israel: 62 years and older for women, and 67 and older for men. The age of 65 is the statistical average between genders, a noted in the paper.

5. A military campaign waged by the IDF in the Gaza Strip between July 8 and August 26. 2014, ending with a ceasefire.

6. Operation Protective Edge, as described by the IDF Spokesperson Unit, the Israeli media, and Wikipedia.

7. Many communities along the Israel-Gaza Strip border were evacuated during the operation, mainly by women and children

8. Symptoms which have been found to increase during war.

9. The Sapir Barometer report deals with the issue extensively.

10. Psychological resilience centers are support centers formed in high-risk areas in Israel, which offer professional therapy services to Israelis of all ages and from all walks of life, prior to, during, and following events such as rocket fire or similar threats. These centers are sponsored by various government ministries, such as the Health, Welfare, and Senior Citizens ministries. (Note that despite the preparations, the elderly made little use of these centers). 
11. Holocaust survivors reviewed in this article were not chosen for it due to their past plight, but because they all fall under the chronological definition of old age customary in Israel. Their past plights alongside the theoretical perception and stigmas about the elderly, has rendered them prima facie, prone to anxiety and depression more than others.

\section{References}

Denise, B., \& Wise, E. (1991). The Relationship among Negative Life Events, Cognition and Depression within Three Generations. The Gerontologist, 31, 397-403. https://doi.org/10.1093/geront/31.3.397

Rosset, U., Tzur, Y., \& Bibi, U. (2015). The Sapir Barometer: The Western Negev's Resilience Index, Sapir Academic College, Sderot, Israel.

Feifel, H., \& Branscomb, A. (1973). Who is Afraid of Death? Journal of Abnormal Psychology, 81, $282-288$. https://doi.org/10.1037/h0034519

Harkabi, Y. (1990). War and Strategy, 132-134, Ma'arachot, Tel Aviv, Israel.

Hobfoll, S. (1998). The Ecology of Stress, 223-225, Hemisphere, New-York.

Lazarus, R. S. (2000). Towards a Better Research on Stress and Coping. American Psychologist, 55, $665-673$. https://doi.org/10.1037/0003-066X.55.6.665

Nowolin, R., \& Siegler, (1993). from: Lumerantz, J. Mental Health and Mental Treatment During Aging. Aging and Gerontology in Israel, Arnold Rosin (ed.), 470, Eshel-Joint, Jerusalem.

Riegel, K. (1976). The Dialectics of Human Development. American Psychologist, 31, 689-700. https://doi.org/10.1037/0003-066X.31.10.689

Ruth, J. E., \& Coleman, P. (1996). Personality and Aging: Coping and Management of the Self in Later life. J.Birren and W. Schaie (Ed.). Handbook of the Psychology of Aging, 4th ed, 308-322, Academic Press, New York.

\section{Copyrights}

Copyright for this article is retained by the author(s), with first publication rights granted to the journal.

This is an open-access article distributed under the terms and conditions of the Creative Commons Attribution license which permits unrestricted use, distribution, and reproduction in any medium, provided the original work is properly cited. 